\title{
Modified Firefly Algorithm-Artificial Neural Network Based Technique for the Prediction of Time-Current Characteristic in Directional Overcurrent Relay
}

\author{
M.H. Hussain ${ }^{1,2}$, I. Musirin ${ }^{3}$, S.R.A. Rahim ${ }^{1,2}$, A.F. Abidin ${ }^{3}$ \\ ${ }^{1}$ School of Electrical System Engineering, Universiti Malaysia Perlis (UniMAP), Arau, Perlis, Malaysia, \\ ${ }^{2}$ Centre of Excellence for Renewable Energy, Universiti Malaysia Perlis (UniMAP), Arau, Perlis, Malaysia, \\ muhdhatta@unimap.edu.my, rafidah@unimap.edu.my \\ ${ }^{3}$ Centre of Electrical Power Engineering Studies \& Faculty of Electrical Engineering, Universiti Teknologi \\ MARA (UiTM) Shah Alam, Selangor, Malaysia,
}

\begin{abstract}
This paper presents an integrated optimal predictor optimization technique termed as Modified Firefly Algorithm-Artificial Neural Network (MFA-ANN) for accurate prediction of Relay Operating Time (ROT). Directional Overcurrent Relays (DOCRs) coordination problem is formulated as Mixed Integer Linear Programming (MILP) problem. The developed techniques have been validated on the IEEE 8-bus systems using MATLAB. The simulation results obtained revealed that the proposed MFA-ANN model has shown the reduction in Root Mean Square Error (RMSE) values as compared with Particle Swarm Optimization-Artificial Neural Network (PSO-ANN) which improved the correlation coefficient of the relay operating time. The proposed MFA-ANN model managed to achieve 0\% RMSE value.
\end{abstract}

Key words : directional overcurrent relay coordination, modified firefly algorithm-artificial neural network, mixed integer linear programming, relay operating time, root mean square error.

\section{INTRODUCTION}

Nowadays, modern power systems are interconnected and protected by Directional Overcurrent Relay (DOCRs). Therefore, protection schemes pose great challenge especially in multi-source networks due to network topology and microprocessor relay. Thus, it becomes very difficult to set the sequence of the relay operations for various faults in power system. Sometimes, it leads to miscoordination between the primary and backup relay pairs with the occurrence of multi-directional fault current in the network.

Abnormal conditions such as fault analysis can be divided into two steps that are determination of the maximum currents that switching devices must interrupt and coordination of protection. Therefore, the overcurrent protection is the most widely used in distribution and transmission system [1], [2]. The setting and coordination of protective relays have become a very tedious operation especially in ring network as compared with radial network system. It can be noted that from the standard relay operating time equation, relay operating time are directly proportional to the Time Multiplier Setting (TMS) and inversely proportional to the pickup current $\left(I_{p}\right)$ setting respectively. Hence, the solution by using this equation requires iterative process with high complexity [3].

The optimization technique is applied to determine each relay best optimal settings corresponding to the fault accordingly since the conventional mathematical based optimization is found to be inaccurate and stuck at local minimum phenomenon [4], [5]. Moreover, the ordinary mathematical based optimization technique may lead to false tripping of healthy section to power outages due to miscoordination [6]. Thus, a reliable optimization technique such as Nature Inspired Metaheuristic Algorithm (NIMA) has been proposed to overcome directional overcurrent relay problems.

Intelligent NIMA swarm families such as Particle Swarm Optimization (PSO), Artificial Bees Colony (ABC), Honey Bee Algorithm (HBA) and Firefly Algorithm (FA) had been used in [7]-[10] to calculate relay settings; TMS and $I_{p}$ in order to minimize relay operating time. However, PSO has a low convergence rate in the iterative process, $\mathrm{ABC}$ and $\mathrm{HBA}$ suffers to look for better solution [11]. FA also can be trapped in local optima due to local search algorithms. Thus, Modified Firefly Algorithm (MFA) is proposed to improve the performance and efficiency of FA to ensure the particles explore into global best region and escape easily from local optima. 
Inappropriate prediction of the time-current characteristics of the DOCR with other non-linear curve fitting within its primary zone has been reviewed [12]. Therefore, an integrated optimal predictor termed as MFA-ANN will predict individual relay operating time at different short circuit current with minimum error using Levenberg-Marquardt algorithm function fitting.

This paper presents the Modified Firefly Algorithm-Artificial Neural Network (MFA-ANN) Based Technique for the Prediction of Time-Current Characteristic in Directional Overcurrent Relay. A comparative study was conducted with respect to Particle Swarm Optimization-Artificial Neural Network (PSO-ANN) performed on the IEEE 8-Bus system. The results revealed that the proposed model has shown the reduction in Root Mean Square Error (RMSE) values.

\section{PROBLEM FORMULATION}

The objective is to determine an appropriate setting of DOCRs during fault occurrence and to predict new relay operating time using Modified Firefly Algorithm- Artificial Neural Network (MFA-ANN) model. These requirements should fulfill according to the relay type, relay characteristics, coordination constraints and objective function.

\subsection{Relay Type}

All the relay types such as electromechanical relay, static relay, digital relay and microprocessor (numerical) relay had been reviewed in terms of speed of response, accuracy time, maintenance and fault disturbance recording. Thus, it can be noted that microprocessor based numerical are often used today as it performs very well and the costing is very low [13].

\subsection{Relay Characteristic}

There are two types of relay characteristics that are linear and non-linear relay characteristic. In this study, the non-linear relay characteristic function based on the standard ANSI/IEEE C37.112-1996 has been used [11]. The relay is extremely inverse type and the relay operating time can be represented as in (1).

$$
t_{i}=\left[\frac{K}{\left(I_{s c_{i}} / I_{p_{i}}\right)^{\alpha}-1}+L\right] T M S_{i}
$$

where $t_{i}$ is the relay operating time for near-end fault of the $\mathrm{i}^{\text {th }}$ relay, $I_{s c \text { i }}$ is the short circuit and $I_{p i}$ is the pickup current setting of the $i^{\text {th }}$ relay. The $T M S_{i}$ of the $i^{\text {th }}$ relay values range continuously from 0.05 to 1 and $I_{p i}$ of the $i^{\text {th }}$ relay values range discretely between 100 and 1000 with a step size of 1 . The constant factor is based on extremely inverse type, $\mathrm{K}=28.2$, $\mathrm{L}$ $=0.1217$ and $\alpha=2$ [11].

\subsection{Coordination Constraints}

Every primary protection must have backup protection for coordination purposes. Thus, primary relay and backup relay are associated each other with coordination constraints. The time interval between primary and backup relay is commonly known as Time Grading Margin (TGM). Basically, TGM depends on relay types, the speed of Circuit Breaker (CB) and relay overshoot time. The TGM can be simplified in terms of equation as in (2).

$$
\Delta t_{p b}=t_{b}-t_{p}-T G M
$$

where $t_{b}$ is the operating time of the backup relay, $t_{p}$ is the operating time of the primary relay and $T G M$ varies from $0.1 \mathrm{~s}$ $-0.5 \mathrm{~s}$ depends on different circumstances.

With faster modern CBs and lower relay overshoot time, $0.2 \mathrm{~s}$ is used in this study.

\subsection{Objective Function}

The objective is to minimize the total operating time of primary relays with optimized values of TMS's and $I_{p}$ 's. To achieve this, the objective function is formulated as in (3).

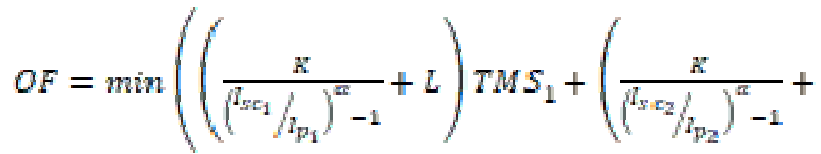

$$
\begin{aligned}
& \text { L) } \left.T M S_{2}+\cdots+\left(\frac{K}{\left(T_{F_{i} /} / r_{F_{i}}\right)^{a}-1}+L\right) T M S_{i}\right)
\end{aligned}
$$

where $O F$ is the objective function

\section{MODIFIED FIREFLY ALGORITHM-ARTIFICIAL NEURAL NETWORK}

FA was proposed by Xin She Yang in 2007 [14] for solving optimization problems. However, there are certain parameters need to be considered as FA can get easily trapped in local optima. The MFA is developed based on FA properties. In this MFA, the alpha parameter is introduced into FA original pseudo-code to increase convergence. The alpha parameter is determined using (4) and (5).

$$
\begin{aligned}
& \delta=1-\left(10^{(-4) / 9)^{(1 / M Q)}}\right. \\
& \sigma=(1-\delta) * \alpha
\end{aligned}
$$


where alpha and delta are parameters to increase convergence [15].

The MFA flowchart can be referred in [11] for the formulation of DOCRs coordination and MFA execution process. Then, the developed MFA is incorporated with ANN, termed as MFA-ANN for prediction of time-current characteristic for all relay operating time in power system network. It is utilized to determine relay operating time in IEEE 8-Bus Transmission system. This study considers the fitness function of MFA and PSO optimization techniques for comparison purposes. Assessment of Root Mean Square Error (RMSE) was conducted to tune the correlation coefficient, $R$ value of the proposed ANN model.

ANN is an adaptive nonlinear information processing system which combined processing units such as real time learning and self-organizing [16]. ANN normally consists of a set of processing units termed as neurons and each neuron is a transfer function. Proper selection of the control variables is a factor for the success of the ANN implementation. Figure 1 illustrates the general configurations of the ANN model. The control variables $X_{1}, X_{2}, \ldots X_{n}$ are the variables to represent the ANN input data. In this research, the control variable $X_{\min }, \ldots X_{\max }$ represents DOCRs TMS while the $I_{p}$ is predetermined value [17].

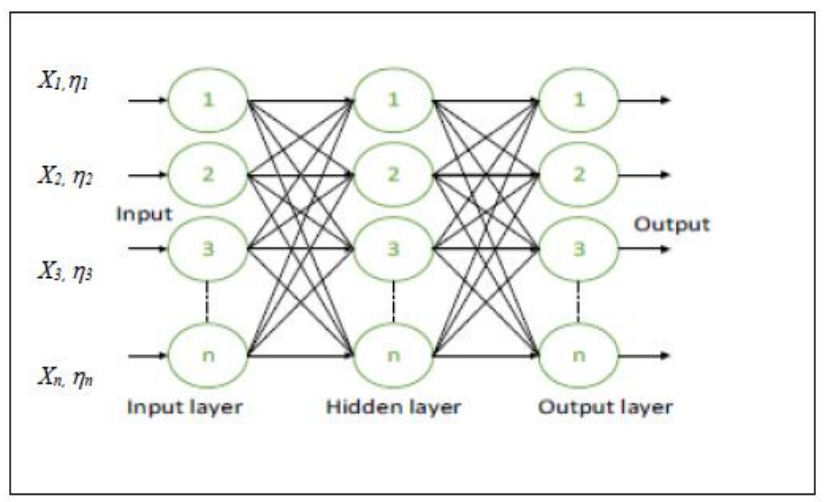

Figure 1: General Configuration of ANN

Table 1: Case Study and Input Variable of ANN Data

\begin{tabular}{|c|c|c|c|}
\hline $\begin{array}{c}\text { Case } \\
\text { Study/Test } \\
\text { System }\end{array}$ & 8-Bus & $\begin{array}{c}\text { ANN } \\
\text { Variable }\end{array}$ & Technique \\
\cline { 2 - 2 } & $\begin{array}{c}\text { No of } \\
\text { DOCRs }\end{array}$ & & \\
\hline $\begin{array}{c}\text { MILP } \\
\text { formulation }\end{array}$ & 14 & $\mathrm{X}_{1}, \mathrm{X}_{2, \ldots}, \mathrm{X}_{\mathrm{n}}$ & MFA-ANN \\
\hline
\end{tabular}

Normally, number of hidden layers are chosen from low values. As suggested by Ismail et al. [18], the number of hidden layer to be ten neurons in the first hidden layer, eight neurons in the second hidden layer and single output. Vishwakawarma et al. [19] mentioned that one hidden layer is sufficient in most applications. Other reference such as in [20] constituted that one hidden layer and four nodes in the hidden layer is chosen. In this study, the initial number of hidden layer is 1 . This value can be increased accordingly to produce better result.

The number of neurons in the hidden layer is also determined heuristically as suggested by [21]. Learning rate also is another factor that controls the performance of the developed ANN which has a value range between 0 and 1 . High learning rate implies high learning capability. However, it can possibly lead to overshoot even the response is fast. This value is also chosen heuristically and typical value of learning rate suggested by Ismail et al. is 0.85 [18].

Learning technique is the technique that controls the learning capabilities of the developed network. For this study Levenberg-Marquardt learning technique is chosen due to its capability in giving fast and accurate responses as suggested by [18].

In order to prepare the data for pattern generation, the two settings of DOCR; TMS and $I_{p}$ are identified as the control variables for the input of ANN. The minimization of relay operating time is determined with an optimal TMS and predetermined values of $I_{p}$. In this study, relay operating time values are used as the targeted output of the proposed model. Data for the MFA depend on the category of targeted output. In this study, the data were generated using the optimal results of MFA. Since MFA only generates one pattern for each process, thus repetitive MFA is conducted to generate the adequate number of patterns required for this study. The proposed MFA-ANN is compared with ABC-ANN for comparison purposes.

The performance of the developed network can be seen from the Root Mean Square Error (RMSE) calculated using the following (6).

$R M S E=\sqrt{\left.\frac{1}{N p} \sum_{p=1}^{N p} \text { (actual } \operatorname{ROT}(p)-\text { estimate } \operatorname{ROT}(p)\right)^{2}}(6)$

where $p$ represents the pattern number and $N P$ denotes the total number of patterns in the corresponding set which contains training or testing. Actual relay operating time (ROT) values are the ANN output, while the estimated ROT values are the targeted output set as the input data of the ANN.

In this study a new optimal predictor model is developed which integrates the MFA-ANN. MFA determines the optimal value of the ANN parameters which is run concurrently. MFA also was utilized to minimize the primary relay operating time while satisfying the time constraint in the system. In this study, MFA-ANN was proposed to minimise the RMSE. The implementation of successful MFA-ANN is expected to reduce the computational time in power system protection especially in overcurrent relay protection and coordination protection. 
The proposed method started by generating control random number generation. Then, $\alpha$ parameter is set in original FA properties to increase convergence. This function is proposed to reduce randomness of the movement factor between fireflies. All the generated individuals which mentioned earlier will be tested on violation. For selection process, the best population was selected which is based on ranking data as initial location of numbers of fireflies. The distance and attractiveness of the fireflies are calculated. The new solutions is evaluated and light intensity is updated. The firefly attractiveness, the distance between any two fireflies are calculated using the Cartesian distance and the movement of firefly is attracted to another more attractive (brighter) firefly were determined. Then, the evaluation of the fitness value, is calculated. The fitness value meant for total minimization primary relay operating time as the objective function.

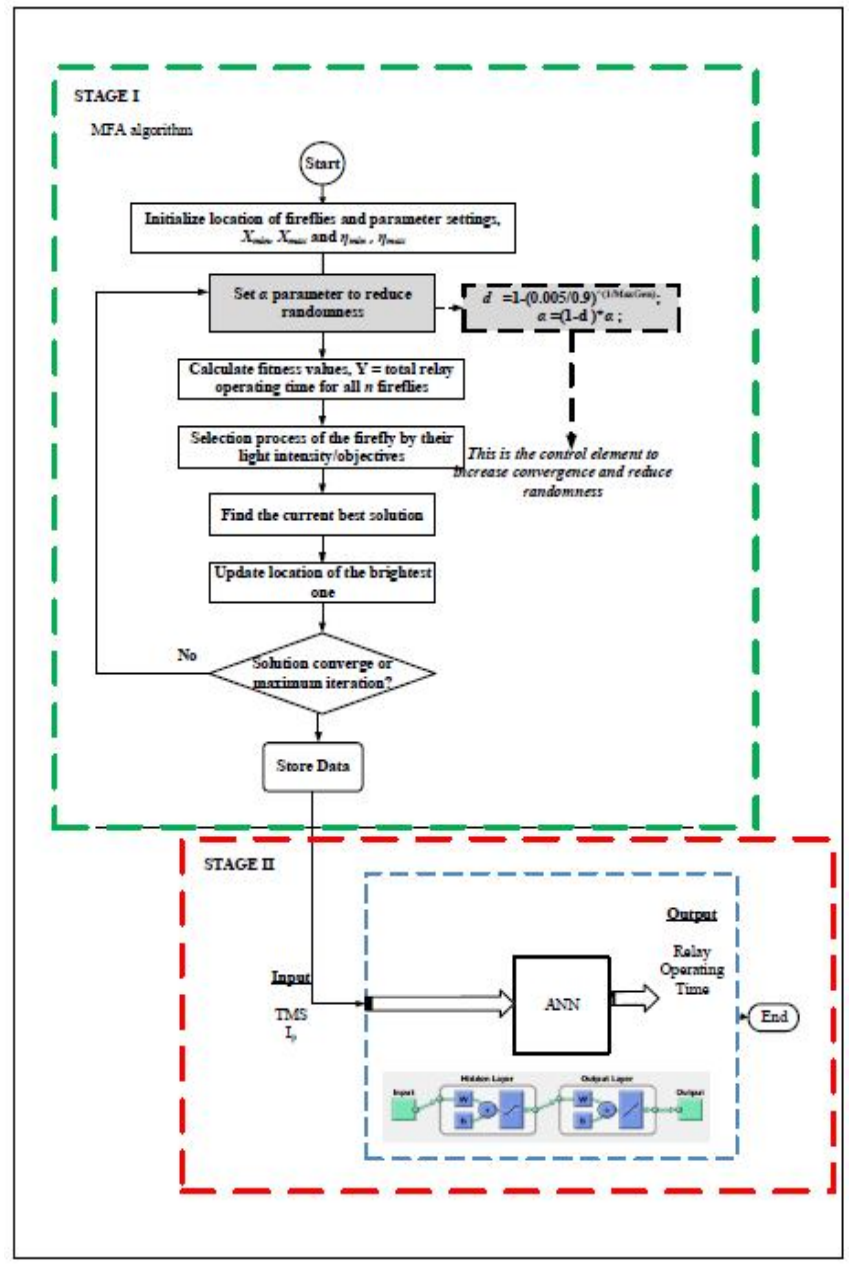

Figure 2: Flowchart DOCR Optimization using MFA-ANN method

Figure 2 presents the algorithm for proposed MFA-ANN method. The proposed method involves two stages. The first stage is the optimisation of DOCR operating time in the system. At this stage, MFA determine the optimal DOCR settings, TMS and $I_{p}$ which lead to minimization of ROT. This will allow adequate information for the ANN in the prediction process as in Stage II. The input data for the ANN are the DOCR settings which are TMS and $I_{p}$ and the output is the relay operating time. The network will be trained with Levenberg-Marquardt backpropagation algorithm. The detailed procedure for the DOCR coordination problem considering relay operating time as the targeted output, are given by the following step-by-step algorithm: -

Steps 1 to 7 follow exactly all the processes of MFA in [11] and the next step is as below.

Step 8 Implement ANN toolbox using neural fitting

Step 9 Determine the suitable ANN structure for the input-target pairs.

Step 10 Train the ANN until the mean squared error (mse) is low enough

Step 11 Test ANN by using the test data set.

\section{RESULTS AND DISCUSSION}

An optimization engine was developed to implement the MFA-ANN technique. The technique was executed on Intel Core i5 $2.53 \mathrm{GHz}$ with $4 \mathrm{~GB}$ RAM and simulated in MATLAB. The proposed method was compared with PSO-ANN algorithm and has been tested on IEEE 8-Bus system. The test system comprises of 8 buses, 7 lines, 2 transformers, 2 generators and 14 DOCRs. The control parameters of MFA technique in Stage 1 are listed in [11]. The single line diagram of the test system and system parameters can be found in [11]. It can be noted that the faults occurred in a transmission line is symmetrical balanced three phase fault and there are 20 primary/backup relay pairs.

MFA-ANN was developed to minimise the RMSE for accurate prediction of time-current characteristics. The proposed technique was tested on the IEEE 8-Bus Transmission System. The targeted output, ROT is analyzed. The analysis is conducted by looking at the optimal settings of DOCR for each relay operating time. The study was conducted in order to determine the total relay operating time $(y)$ with optimal TMS $(X)$ and predetermined $I_{p}(\eta)$ which also known as MILP formulation. This mono-objective optimization is chosen based on the 5 best performances from exhaustive 30 trial simulations. Appendix displayed the obtained values for the training with least mean square error between actual output and target output for the best 5 trials from the applied MFA-ANN model and PSO-ANN model respectively.

Table 2: Case Study for prediction of ROT

\begin{tabular}{|c|c|c|}
\hline Case Study & Targeted Output & $\begin{array}{c}\text { Control } \\
\text { Variables Input }\end{array}$ \\
\hline MILP & $y$ & $x_{1}, x_{2}, \ldots, x_{n}$ \\
\hline
\end{tabular}

The idea is to minimise the percentage of RMSE using the proposed MFA-ANN. For validation purposes, the results obtained were compared with PSO-ANN respectively. Table 3 
tabulates the number of samples for training, validation and testing process for the IEEE 8-Bus system study.

Table 3: Number of Samples for Training, Validation and Testing for IEEE 8-Bus System

\begin{tabular}{|c|c|}
\hline \multirow{2}{*}{} & IEEE 8-Bus \\
\cline { 2 - 2 } & Samples \\
\hline No of Training Pattern & 48 \\
\hline No of Validation Pattern & 11 \\
\hline No of Testing Pattern & 11 \\
\hline
\end{tabular}

The analysis is conducted by taking 5 set of best trials obtained [11]. Figure 3 illustrates the variations of mean squared error (mse) of the incremental epochs. The results show the best validation performance of $1.0815 \mathrm{e}^{-14}$ optimized within 84 epochs. The calculated RMSE error is $0 \%$.

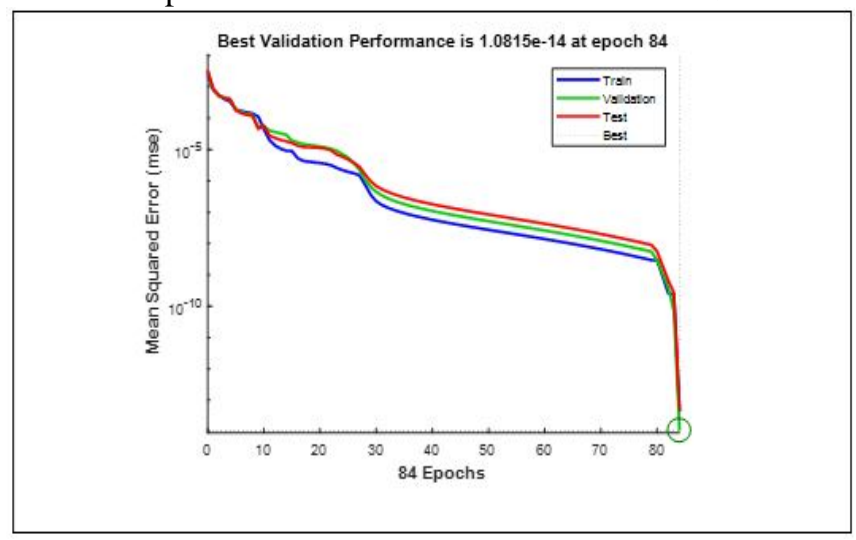

Figure 3: Performance for ROT using MFA-ANN

As comparison with MFA-ANN, PSO-ANN is also modeled and the results is shown in Figure 4. The results show the performance is 0.00011484 at both epoch within iteration is 50 epochs. The calculated RMSE error is $1.5019 \%$ which implies the deviation between the overall PSO-ANN outputs and targeted output.

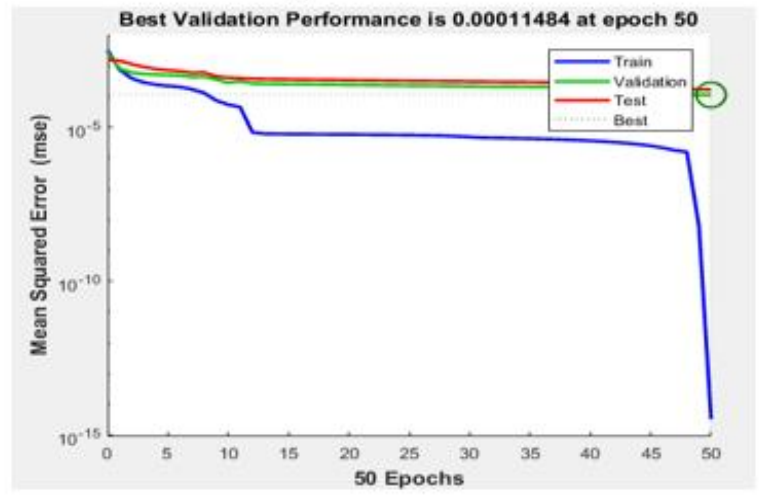

Figure 4: Performance for ROT using PSO-ANN

Figure 5 illustrates the regression analysis of ROT using MFA-ANN. The results for regression analysis are presented for the training, validation, testing and overall process. As can be seen, the correlation coefficient value during training is, $\mathrm{R}=1$. On the other hand, the $\mathrm{R}=1.0$ during validation, testing and all data. This implies high accuracy has been achieved when MFA-ANN was implemented to in the IEEE 8-bus system.

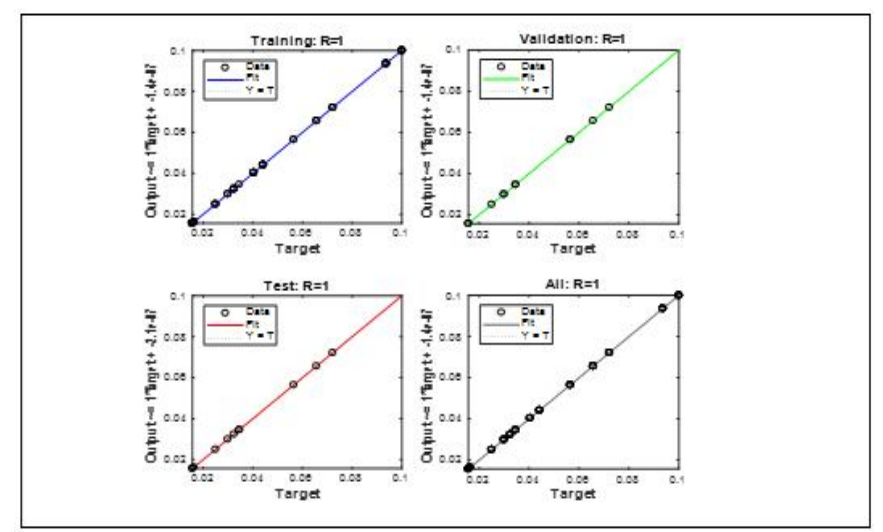

Figure 5: Regression Analysis for ROT using MFA-ANN

Similar study was also performed using PSO-ANN. As can be seen in Figure 6, the correlation coefficient value during training is $\mathrm{R}=1$ but the corresponding $\mathrm{R}$ value is 0.91371 during validation for PSO-ANN. During testing the value of $\mathrm{R}$ is 0.91346 for testing and 0.97102 for all data. Although the value for training, validation, testing and all data is different, high accuracy has been achieved.

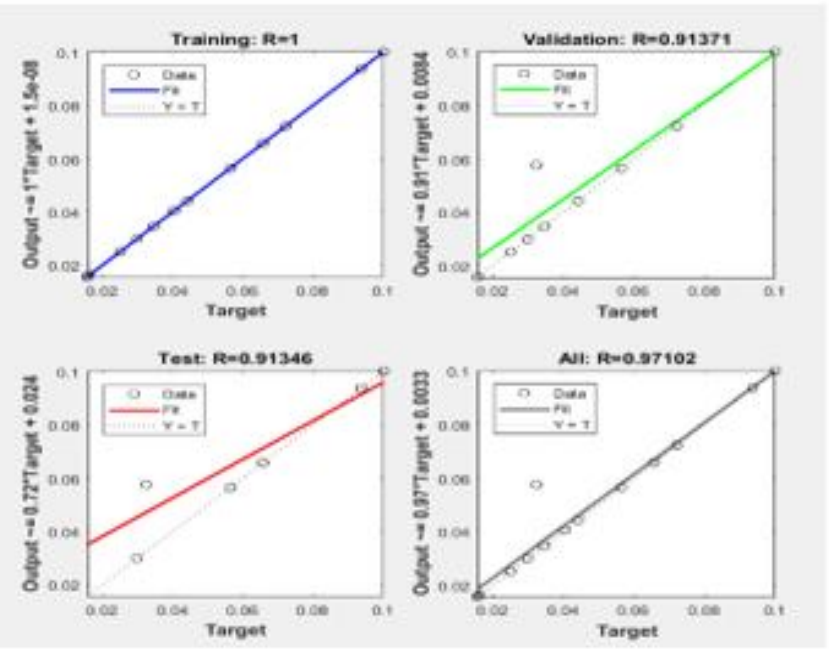

Figure 6: Regression Analysis for ROT using PSO-ANN

Comparative studies was conducted between the developed MFA-ANN and PSO-ANN for each pattern number. In this section, the comparative study was done by analysing the RMSE values and the best relay operating time and the proposed MFA-ANN with PSO-ANN. The comparisons on the system performance of RMSE between the MFA-ANN and PSO-ANN in 8-Bus system is presented in Figure 7. It shows that the proposed MFA-ANN for relay operating time gives minimum RMSE error as compared to PSO-ANN. The output ROT using MFA-ANN also shows at minimum value compared to PSO-ANN. The calculated RMSE error for 
M.H. Hussain et al., International Journal of Emerging Trends in Engineering Research, 8(1.1), 2020, 170- 178

MFA-ANN and PSO-ANN are $0 \%$ and $1.50194 \%$ respectively. It shows the RMSE value for MFA-ANN is better than PSO-ANN.

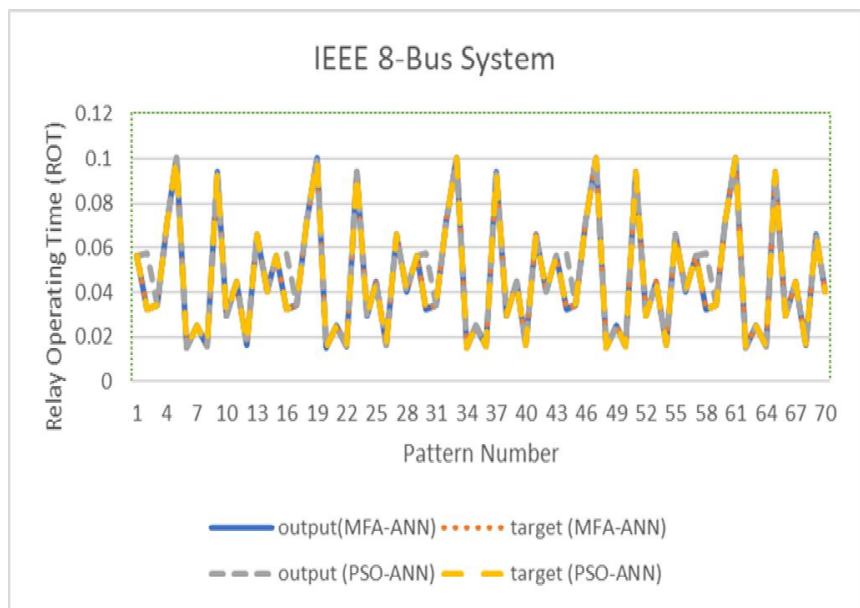

Figure 7: Difference between Targeted Output and Output Of the Proposed MFA-ANN and PSO-ANN for ROT

The implementation of the proposed MFA-ANN in the prediction of ROT managed to achieve significant results as compared to PSO-ANN. It is found that the proposed MFA-ANN has achieved better RMSE and improved correlation coefficient value, $R$, value as a measure of the correlation between output and target in IEEE 8-Bus system. Closeness of $\mathrm{R}$ value to 1.0 indicates the perfection of the developed MFA-ANN model to perform the prediction process. It also can be highlighted that the proposed technique is feasible to solve coordination time in a protection system.

\section{CONCLUSION}

Modified Firefly Algorithm-Artificial Neural Network model has been presented in this paper to predict relay operating time. From the results, the proposed technique outperformed Particle Swarm Optimization-Artificial Neural Network with the best $\mathrm{R}$ value equal to 1 and the best RMSE is $0 \%$. It also revealed that the Levenberg-Marquardt non-linear function fitting algorithm application on solving the proposed technique predicted relay operating time effectively with minimum mean square error between the target output and the actual output. Thus, it could be utilized by the protection engineer for minimizing the relay operating time that includes preventing the miscoordination occurs on the primary and backup relay pairs in the transmission systems.

\section{APPENDIX}

Table 4: Levenberg-Marquardt algorithm training results for MFA-ANN for 5 best trials

\begin{tabular}{|c|c|c|c|c|c|}
\hline $\begin{array}{l}\text { Trial } \\
\text { s No }\end{array}$ & $\overline{\text { DOCR }}$ & ROT & $\begin{array}{l}\text { Targe } \\
\text { t Time }\end{array}$ & $\begin{array}{l}\text { MFA-ANN } \\
\text { Time }\end{array}$ & $\begin{array}{c}\text { Mean } \\
\text { Square } \\
\text { Error } \\
\text { (MSE) }\end{array}$ \\
\hline \multirow{14}{*}{$\begin{array}{l}1^{\text {st }} \\
\text { Trial }\end{array}$} & R1 & $\begin{array}{c}0.056 \\
5\end{array}$ & 0.0565 & 0.0565 & $\begin{array}{c}-2.46 \mathrm{E}-0 \\
8 \\
\end{array}$ \\
\hline & R2 & $\begin{array}{c}0.032 \\
4\end{array}$ & 0.0324 & 0.0324 & $\begin{array}{c}-1.52 \mathrm{E}-0 \\
7\end{array}$ \\
\hline & R3 & $\begin{array}{c}0.034 \\
6 \\
\end{array}$ & 0.0346 & 0.0346 & $8.91 \mathrm{E}-11$ \\
\hline & R4 & $\begin{array}{c}0.072 \\
2 \\
\end{array}$ & 0.0722 & 0.0722 & $\begin{array}{c}-5.90 \mathrm{E}-0 \\
8 \\
\end{array}$ \\
\hline & R5 & $\begin{array}{c}0.100 \\
1\end{array}$ & 0.1001 & 0.1001 & 8.33E-08 \\
\hline & R6 & $\begin{array}{c}0.015 \\
6\end{array}$ & 0.0156 & 0.0156 & 4.93E-08 \\
\hline & R7 & $\begin{array}{c}0.025 \\
0\end{array}$ & 0.0250 & 0.0250 & $1.50 \mathrm{E}-07$ \\
\hline & $\mathrm{R} 8$ & $\begin{array}{c}0.015 \\
7\end{array}$ & 0.0157 & 0.0157 & $\begin{array}{c}-3.92 \mathrm{E}-0 \\
8\end{array}$ \\
\hline & R9 & $\begin{array}{c}0.093 \\
7\end{array}$ & 0.0937 & 0.0937 & $1.34 \mathrm{E}-07$ \\
\hline & R10 & $\begin{array}{c}0.029 \\
9\end{array}$ & 0.0299 & 0.0299 & $2.09 \mathrm{E}-07$ \\
\hline & R11 & $\begin{array}{c}0.044 \\
2 \\
\end{array}$ & 0.0442 & 0.0442 & $\begin{array}{c}-1.87 \mathrm{E}-0 \\
8 \\
\end{array}$ \\
\hline & R12 & $\begin{array}{c}0.016 \\
3\end{array}$ & 0.0163 & 0.0163 & $6.46 \mathrm{E}-07$ \\
\hline & R13 & $\begin{array}{c}0.065 \\
7 \\
\end{array}$ & 0.0657 & 0.0657 & $\begin{array}{c}-7.47 \mathrm{E}-0 \\
9 \\
\end{array}$ \\
\hline & R14 & $\begin{array}{c}0.040 \\
4\end{array}$ & 0.0404 & 0.0404 & $\begin{array}{c}-3.37 \mathrm{E}-1 \\
0\end{array}$ \\
\hline \multirow{10}{*}{$\begin{array}{c}2^{\text {nd }} \\
\text { Trial }\end{array}$} & R1 & $\begin{array}{c}0.056 \\
5\end{array}$ & 0.0565 & 0.0565 & $\begin{array}{c}-2.46 \mathrm{E}-0 \\
8\end{array}$ \\
\hline & $\mathrm{R} 2$ & $\begin{array}{c}0.032 \\
4\end{array}$ & 0.0324 & 0.0324 & $\begin{array}{c}-1.52 \mathrm{E}-0 \\
7\end{array}$ \\
\hline & R3 & $\begin{array}{c}0.034 \\
6\end{array}$ & 0.0346 & 0.0346 & $8.91 \mathrm{E}-11$ \\
\hline & $\mathrm{R} 4$ & $\begin{array}{c}0.072 \\
2 \\
\end{array}$ & 0.0722 & 0.0722 & $\begin{array}{c}-5.90 \mathrm{E}-0 \\
8 \\
\end{array}$ \\
\hline & R5 & $\begin{array}{c}0.100 \\
1\end{array}$ & 0.1001 & 0.1001 & 8.33E-08 \\
\hline & R6 & $\begin{array}{c}0.015 \\
6\end{array}$ & 0.0156 & 0.0156 & 4.93E-08 \\
\hline & R7 & $\begin{array}{c}0.025 \\
0 \\
\end{array}$ & 0.0250 & 0.0250 & $1.50 \mathrm{E}-07$ \\
\hline & R8 & $\begin{array}{c}0.015 \\
7 \\
\end{array}$ & 0.0157 & 0.0157 & $\begin{array}{c}-3.92 \mathrm{E}-0 \\
8 \\
\end{array}$ \\
\hline & R9 & $\begin{array}{c}0.093 \\
7 \\
\end{array}$ & 0.0937 & 0.0937 & $1.34 \mathrm{E}-07$ \\
\hline & R10 & 0.029 & 0.0299 & 0.0299 & $2.09 \mathrm{E}-07$ \\
\hline
\end{tabular}


M.H. Hussain et al., International Journal of Emerging Trends in Engineering Research, 8(1.1), 2020, 170- 178

\begin{tabular}{|c|c|c|c|c|c|}
\hline & & 9 & & & \\
\hline & R11 & $\begin{array}{c}0.044 \\
2\end{array}$ & 0.0442 & 0.0442 & $\begin{array}{c}-1.87 \mathrm{E}-0 \\
8\end{array}$ \\
\hline & R12 & $\begin{array}{c}0.016 \\
3\end{array}$ & 0.0163 & 0.0163 & $6.46 \mathrm{E}-07$ \\
\hline & R13 & $\begin{array}{c}0.065 \\
7 \\
\end{array}$ & 0.0657 & 0.0657 & $\begin{array}{c}-7.47 \mathrm{E}-0 \\
9\end{array}$ \\
\hline & R14 & $\begin{array}{c}0.040 \\
4\end{array}$ & 0.0404 & 0.0404 & $\begin{array}{c}-3.37 \mathrm{E}-1 \\
0\end{array}$ \\
\hline \multirow{14}{*}{$\begin{array}{l}14^{\text {th }} \\
\text { Trial }\end{array}$} & R1 & $\begin{array}{c}0.056 \\
5\end{array}$ & 0.0565 & 0.0565 & $\begin{array}{c}-2.46 \mathrm{E}-0 \\
8\end{array}$ \\
\hline & $\mathrm{R} 2$ & $\begin{array}{c}0.032 \\
4\end{array}$ & 0.0324 & 0.0324 & $\begin{array}{c}-1.52 \mathrm{E}-0 \\
7 \\
\end{array}$ \\
\hline & R3 & $\begin{array}{c}0.034 \\
6 \\
\end{array}$ & 0.0346 & 0.0346 & 8.91E-11 \\
\hline & R4 & $\begin{array}{c}0.072 \\
2\end{array}$ & 0.0722 & 0.0722 & $\begin{array}{c}-5.90 \mathrm{E}-0 \\
8\end{array}$ \\
\hline & R5 & $\begin{array}{c}0.100 \\
1\end{array}$ & 0.1001 & 0.1001 & 8.33E-08 \\
\hline & R6 & $\begin{array}{c}0.015 \\
6\end{array}$ & 0.0156 & 0.0156 & 4.93E-08 \\
\hline & R7 & $\begin{array}{c}0.025 \\
0\end{array}$ & 0.0250 & 0.0250 & $1.50 \mathrm{E}-07$ \\
\hline & $\mathrm{R} 8$ & $\begin{array}{c}0.015 \\
7 \\
\end{array}$ & 0.0157 & 0.0157 & $\begin{array}{c}-3.92 \mathrm{E}-0 \\
8 \\
\end{array}$ \\
\hline & R9 & $\begin{array}{c}0.093 \\
7\end{array}$ & 0.0937 & 0.0937 & $1.34 \mathrm{E}-07$ \\
\hline & R10 & $\begin{array}{c}0.029 \\
9\end{array}$ & 0.0299 & 0.0299 & 2.09E-07 \\
\hline & R11 & $\begin{array}{c}0.044 \\
2 \\
\end{array}$ & 0.0442 & 0.0442 & $\begin{array}{c}-1.87 \mathrm{E}-0 \\
8 \\
\end{array}$ \\
\hline & $\mathrm{R} 12$ & $\begin{array}{c}0.016 \\
3 \\
\end{array}$ & 0.0163 & 0.0163 & $6.46 \mathrm{E}-07$ \\
\hline & R13 & $\begin{array}{c}0.065 \\
7 \\
\end{array}$ & 0.0657 & 0.0657 & $\begin{array}{c}-7.47 \mathrm{E}-0 \\
9 \\
\end{array}$ \\
\hline & R14 & $\begin{array}{c}0.040 \\
4\end{array}$ & 0.0404 & 0.0404 & $\begin{array}{c}-3.37 \mathrm{E}-1 \\
0 \\
\end{array}$ \\
\hline \multirow{10}{*}{$\begin{array}{l}29^{\text {th }} \\
\text { Trial }\end{array}$} & R1 & $\begin{array}{c}0.056 \\
5\end{array}$ & 0.0565 & 0.0565 & $\begin{array}{c}-2.46 \mathrm{E}-0 \\
8\end{array}$ \\
\hline & $\mathrm{R} 2$ & $\begin{array}{c}0.032 \\
4\end{array}$ & 0.0324 & 0.0324 & $\begin{array}{c}-1.52 \mathrm{E}-0 \\
7\end{array}$ \\
\hline & $\mathrm{R} 3$ & $\begin{array}{c}0.034 \\
6 \\
\end{array}$ & 0.0346 & 0.0346 & $8.91 \mathrm{E}-11$ \\
\hline & $\mathrm{R} 4$ & $\begin{array}{c}0.072 \\
2 \\
\end{array}$ & 0.0722 & 0.0722 & $\begin{array}{c}-5.90 \mathrm{E}-0 \\
8 \\
\end{array}$ \\
\hline & R5 & $\begin{array}{c}0.100 \\
1 \\
\end{array}$ & 0.1001 & 0.1001 & 8.33E-08 \\
\hline & R6 & $\begin{array}{c}0.015 \\
6 \\
\end{array}$ & 0.0156 & 0.0156 & 4.93E-08 \\
\hline & R7 & $\begin{array}{c}0.025 \\
0 \\
\end{array}$ & 0.0250 & 0.0250 & $1.50 \mathrm{E}-07$ \\
\hline & $\mathrm{R} 8$ & $\begin{array}{c}0.015 \\
7 \\
\end{array}$ & 0.0157 & 0.0157 & $\begin{array}{c}-3.92 \mathrm{E}-0 \\
8 \\
\end{array}$ \\
\hline & R9 & $\begin{array}{c}0.093 \\
7 \\
\end{array}$ & 0.0937 & 0.0937 & $1.34 \mathrm{E}-07$ \\
\hline & $\mathrm{R} 10$ & 0.029 & 0.0299 & 0.0299 & $2.09 \mathrm{E}-07$ \\
\hline
\end{tabular}

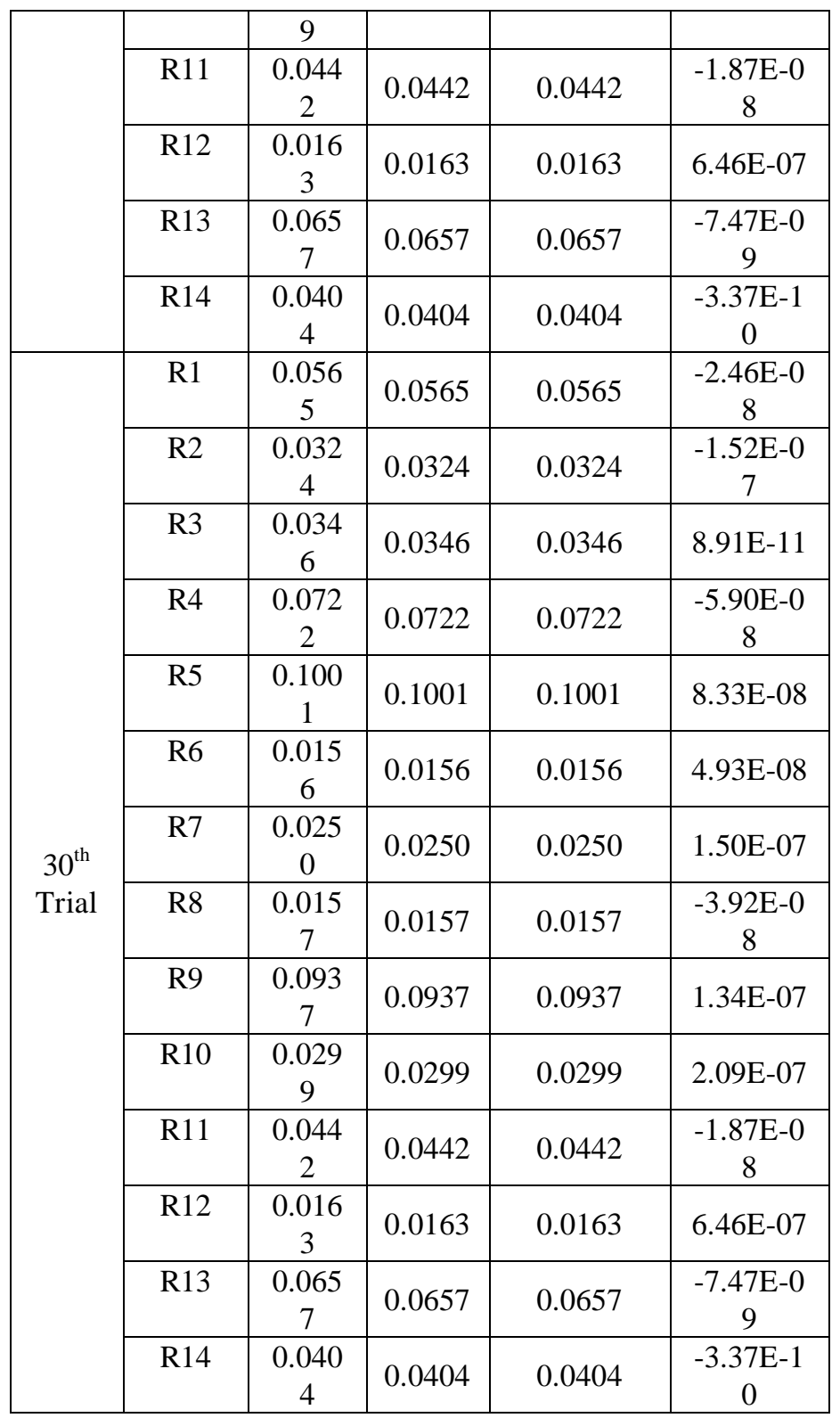

Table 5: Levenberg-Marquardt algorithm training results for PSO-ANN for 5 best trials

\begin{tabular}{|c|c|c|c|c|c|}
\hline $\begin{array}{c}\text { Trials } \\
\text { No }\end{array}$ & DOCR & ROT & $\begin{array}{c}\text { Targe } \\
\text { t Time }\end{array}$ & $\begin{array}{c}\text { MFA-ANN } \\
\text { Time }\end{array}$ & $\begin{array}{c}\text { Mean } \\
\text { Square } \\
\text { Error } \\
\text { (MSE) }\end{array}$ \\
\hline \multirow{4}{*}{$\begin{array}{c}1^{\text {st }} \\
\text { Trial }\end{array}$} & R1 & 0.0565 & 0.0565 & 0.0565 & $1.81 \mathrm{E}-09$ \\
\cline { 2 - 6 } & R3 & $\begin{array}{c}0.0648 \\
1\end{array}$ & 0.0324 & 0.057532 & -0.02513 \\
\cline { 2 - 6 } & R4 & 0.0722 & 0.0722 & 0.0722 & $8.10 \mathrm{E}-10$ \\
\cline { 2 - 6 } & R5 & 0.1001 & 0.1001 & 0.1001 & $1.64 \mathrm{E}-08$ \\
\cline { 2 - 6 } & R6 & 0.0156 & 0.0156 & 0.0156 & $7.79 \mathrm{E}-08$ \\
\cline { 2 - 6 } & R7 & 0.0250 & 0.0250 & 0.0250 & $-9.63 \mathrm{E}-0$ \\
8
\end{tabular}


M.H. Hussain et al., International Journal of Emerging Trends in Engineering Research, 8(1.1), 2020, 170- 178

\begin{tabular}{|c|c|c|c|c|c|}
\hline & R8 & 0.0157 & 0.0157 & 0.0157 & $1.88 \mathrm{E}-08$ \\
\hline & R9 & 0.0937 & 0.0937 & 0.0937 & $1.19 \mathrm{E}-07$ \\
\hline & R10 & 0.0299 & 0.0299 & 0.0299 & $\begin{array}{c}-2.01 \mathrm{E}-0 \\
8\end{array}$ \\
\hline & R11 & 0.0442 & 0.0442 & 0.0442 & $7.88 \mathrm{E}-08$ \\
\hline & R12 & 0.0163 & 0.0163 & 0.0163 & $\begin{array}{c}-1.16 \mathrm{E}-0 \\
8\end{array}$ \\
\hline & R13 & 0.0657 & 0.0657 & 0.0657 & $7.43 \mathrm{E}-09$ \\
\hline & R14 & 0.0404 & 0.0404 & 0.0404 & $\begin{array}{c}-3.26 \mathrm{E}-0 \\
8\end{array}$ \\
\hline \multirow{14}{*}{$\begin{array}{l}2^{\text {nd }} \\
\text { Trial }\end{array}$} & $\mathrm{R} 1$ & 0.0565 & 0.0565 & 0.0565 & $1.81 \mathrm{E}-09$ \\
\hline & R2 & 0.0324 & 0.0324 & 0.057532 & -0.02513 \\
\hline & R3 & 0.0346 & 0.0346 & 0.0346 & $2.42 \mathrm{E}-09$ \\
\hline & R4 & 0.0722 & 0.0722 & 0.0722 & $8.10 \mathrm{E}-10$ \\
\hline & $\mathrm{R} 5$ & 0.1001 & 0.1001 & 0.1001 & $1.64 \mathrm{E}-08$ \\
\hline & R6 & 0.0156 & 0.0156 & 0.0156 & 7.79E-08 \\
\hline & $\mathrm{R} 7$ & 0.0250 & 0.0250 & 0.0250 & $\begin{array}{c}-9.63 \mathrm{E}-0 \\
8\end{array}$ \\
\hline & R8 & 0.0157 & 0.0157 & 0.0157 & $1.88 \mathrm{E}-08$ \\
\hline & R9 & 0.0937 & 0.0937 & 0.0937 & $1.19 \mathrm{E}-07$ \\
\hline & R10 & 0.0299 & 0.0299 & 0.0299 & $\begin{array}{c}-2.01 \mathrm{E}-0 \\
8\end{array}$ \\
\hline & R11 & 0.0442 & 0.0442 & 0.0442 & $7.88 \mathrm{E}-08$ \\
\hline & R12 & 0.0163 & 0.0163 & 0.0163 & $\begin{array}{c}-1.16 \mathrm{E}-0 \\
8\end{array}$ \\
\hline & R13 & 0.0657 & 0.0657 & 0.0657 & $7.43 \mathrm{E}-09$ \\
\hline & R14 & 0.0404 & 0.0404 & 0.0404 & $\begin{array}{c}-3.26 \mathrm{E}-0 \\
8\end{array}$ \\
\hline \multirow{14}{*}{$\begin{array}{l}14^{\text {th }} \\
\text { Trial }\end{array}$} & R1 & 0.0565 & 0.0565 & 0.0565 & 1.81E-09 \\
\hline & $\mathrm{R} 2$ & 0.0324 & 0.0324 & 0.057532 & -0.02513 \\
\hline & R3 & 0.0346 & 0.0346 & 0.0346 & $2.42 \mathrm{E}-09$ \\
\hline & $\mathrm{R} 4$ & 0.0722 & 0.0722 & 0.0722 & $8.10 \mathrm{E}-10$ \\
\hline & R5 & 0.1001 & 0.1001 & 0.1001 & $1.64 \mathrm{E}-08$ \\
\hline & R6 & 0.0156 & 0.0156 & 0.0156 & $7.79 \mathrm{E}-08$ \\
\hline & R7 & 0.0250 & 0.0250 & 0.0250 & $\begin{array}{c}-9.63 \mathrm{E}-0 \\
8\end{array}$ \\
\hline & R8 & 0.0157 & 0.0157 & 0.0157 & $1.88 \mathrm{E}-08$ \\
\hline & R9 & 0.0937 & 0.0937 & 0.0937 & $1.19 \mathrm{E}-07$ \\
\hline & R10 & 0.0299 & 0.0299 & 0.0299 & $\begin{array}{c}-2.01 \mathrm{E}-0 \\
8\end{array}$ \\
\hline & R11 & 0.0442 & 0.0442 & 0.0442 & $7.88 \mathrm{E}-08$ \\
\hline & R12 & 0.0163 & 0.0163 & 0.0163 & $\begin{array}{c}-1.16 \mathrm{E}-0 \\
8\end{array}$ \\
\hline & $\mathrm{R} 13$ & 0.0657 & 0.0657 & 0.0657 & 7.43E-09 \\
\hline & R14 & 0.0404 & 0.0404 & 0.0404 & $\begin{array}{c}-3.26 \mathrm{E}-0 \\
8\end{array}$ \\
\hline \multirow{8}{*}{$\begin{array}{l}29^{\text {th }} \\
\text { Trial }\end{array}$} & $\mathrm{R} 1$ & 0.0565 & 0.0565 & 0.0565 & $1.81 \mathrm{E}-09$ \\
\hline & R2 & 0.0324 & 0.0324 & 0.057532 & -0.02513 \\
\hline & R3 & 0.0346 & 0.0346 & 0.0346 & $2.42 \mathrm{E}-09$ \\
\hline & $\mathrm{R} 4$ & 0.0722 & 0.0722 & 0.0722 & $8.10 \mathrm{E}-10$ \\
\hline & R5 & 0.1001 & 0.1001 & 0.1001 & $1.64 \mathrm{E}-08$ \\
\hline & R6 & 0.0156 & 0.0156 & 0.0156 & 7.79E-08 \\
\hline & R7 & 0.0250 & 0.0250 & 0.0250 & $\begin{array}{c}-9.63 \mathrm{E}-0 \\
8 \\
\end{array}$ \\
\hline & $\mathrm{R} 8$ & 0.0157 & 0.0157 & 0.0157 & $1.88 \mathrm{E}-08$ \\
\hline
\end{tabular}

\begin{tabular}{|c|c|c|c|c|c|}
\hline & R9 & 0.0937 & 0.0937 & 0.0937 & $1.19 \mathrm{E}-07$ \\
\hline & R10 & 0.0299 & 0.0299 & 0.0299 & $\begin{array}{c}-2.01 \mathrm{E}-0 \\
8\end{array}$ \\
\hline & R11 & 0.0442 & 0.0442 & 0.0442 & $7.88 \mathrm{E}-08$ \\
\hline & R12 & 0.0163 & 0.0163 & 0.0163 & $\begin{array}{c}-1.16 \mathrm{E}-0 \\
8\end{array}$ \\
\hline & R13 & 0.0657 & 0.0657 & 0.0657 & $7.43 \mathrm{E}-09$ \\
\hline & R14 & 0.0404 & 0.0404 & 0.0404 & $\begin{array}{c}-3.26 \mathrm{E}-0 \\
8\end{array}$ \\
\hline \multirow{14}{*}{$\begin{array}{l}30^{\text {th }} \\
\text { Trial }\end{array}$} & $\mathrm{R} 1$ & 0.0565 & 0.0565 & 0.0565 & $1.81 \mathrm{E}-09$ \\
\hline & $\mathrm{R} 2$ & 0.0324 & 0.0324 & 0.057532 & -0.02513 \\
\hline & R3 & 0.0346 & 0.0346 & 0.0346 & $2.42 \mathrm{E}-09$ \\
\hline & R4 & 0.0722 & 0.0722 & 0.0722 & $8.10 \mathrm{E}-10$ \\
\hline & R5 & 0.1001 & 0.1001 & 0.1001 & $1.64 \mathrm{E}-08$ \\
\hline & R6 & 0.0156 & 0.0156 & 0.0156 & 7.79E-08 \\
\hline & R7 & 0.0250 & 0.0250 & 0.0250 & $\begin{array}{c}-9.63 \mathrm{E}-0 \\
8\end{array}$ \\
\hline & $\mathrm{R} 8$ & 0.0157 & 0.0157 & 0.0157 & $1.88 \mathrm{E}-08$ \\
\hline & R9 & 0.0937 & 0.0937 & 0.0937 & 1.19E-07 \\
\hline & R10 & 0.0299 & 0.0299 & 0.0299 & $\begin{array}{c}-2.01 \mathrm{E}-0 \\
8\end{array}$ \\
\hline & R11 & 0.0442 & 0.0442 & 0.0442 & $7.88 \mathrm{E}-08$ \\
\hline & R12 & 0.0163 & 0.0163 & 0.0163 & $\begin{array}{c}-1.16 \mathrm{E}-0 \\
8\end{array}$ \\
\hline & R13 & 0.0657 & 0.0657 & 0.0657 & $7.43 \mathrm{E}-09$ \\
\hline & R14 & 0.0404 & 0.0404 & 0.0404 & $\begin{array}{c}-3.26 \mathrm{E}-0 \\
8\end{array}$ \\
\hline
\end{tabular}

\section{ACKNOWLEDGEMENT}

The authors would like to acknowledge the support from the Fundamental Research Grant Scheme (FRGS) under a grant number of FRGS/1/2019/TK07/UNIMAP/02/9 from the Ministry of Education (MOE) Malaysia.

\section{REFERENCES}

1. F. Coffele, C. Booth, and A. Dysko. An adaptive overcurrent protection scheme for distribution networks, IEEE Trans. on Power Delivery, Vol. 30, No. 2, pp. 561-568, February 2014.

2. X. Pei, Z. Chen, S. Wang, and K. Yang. Overcurrent protection for inverter-based distributed generation system, in Proc. IEEE Energy Conversion Congress and Exposition, ECCE 2015, 2015, pp. 2328-2332.

3. Y. Damchi, J. Sadeh,, and H.R. Mashhadi. Optimal coordination of distance and directional overcurrent relays considering different network topologies, Iranian Journal of Electrical and Electronic Engineering., vol. 11, no. 3, pp. 231-240, 2015.

4. C. Gammara, and J. M. Guerrero. Computational optimization techniques applied to microgrids planning: A review, Elsevier, Renewable and 
Sustainable Energy Reviews, vol. 48, no. C, pp. 413-424, August 2015.

5. S. Auon Raza, T. Mahmood, S.B. Ali Bukhari, and M. Kashif Nawaz. Application of optimization techniques in overcurrent relay coordination-a review, World Applied Sciences Journal, vol. 28, no. 2, pp. 259-265, January 2013.

6. R. Mohammadi, H.A. Abyaneh, H.M. Rudsari, S.H. Fathi, and H. Rastegar. Overcurrent relays coordination considering the priority of constraints, IEEE Trans. on Power Delivery, vol. 26, no. 3, pp. 1927-1938, June 2011.

7. M.R. Asadi, and S.M. Kouhsari. Optimal overcurrent relays coordination using particle swarm optimization algorithm, in Proc. IEEE/PES Power Systems Conference and Exposition. PSCE 2009, 2009, pp. 1-6.

8. D. Uthisunthorn, P. Pao La Or, and T. Kulworawanichpong, Optimal overcurrent relay coordination using artificial bees colony algorithm, in Proc. ECTI-CON $2011-8^{\text {th }}$ Electrical Engineering/Electronics, Computer, Telecommunications and Information Technology (ECTI) Association of Thailand Conference, 2011, pp. 65-70.

9. V. Ratschi, J. Gholinezad, and P. Farhang, Optimal coordination of overcurrent relays using Honey Bee Algorithm, in Proc. International Congress on Ultra-Modern Telecommunications and Control Systems and Workshops, ICUMT 2010, 2010, pp. 401-405.

10. S.V. Purani, N.S. Gandhi, and M.R. Jaykhedkar. Optimal overcurrent relay coordination using firefly algorithm: A meta heuristic approach, VIER Journal of Engineering Research, pp. 1-5, August 2015.

11. M.H. Hussain, I. Musirin, A.F. Abidin, and S.R.A. Rahim. Multi-Objective Approach for solving directional overcurrent relay problem using modified firefly algorithm, International Journal of Computing, Communications and Instrumentation Engineering, vol.3, Issue 1, pp. 21-26, June 2016.

12. O. Emmanuel, M.L. Othman, H. Hizam, N. Rezaei, and M.M. Othman. Time-Current characteristic curve prediction for directional overcurrent relays in interconnected network using artificial neural network, ARPN Journal of Engineering and Applied Science, vol. 10, no. 22, pp. 10679-10685, December 2015.

13. K. Zimmerman, and D. Costello, Fundamentals and improvements for directional relays, in Proc. $63^{\text {rd }}$ Annual conference for protective relay engineers, 2010, pp. 1-13.

14. X.S. Yang, Firefly algorithm, Levi flights and global optimization, in Proc. Research and Development in Intelligent Systems XXVI: Incorporating Applications and Innovations in Intelligent Systems XVII, 2010, pp. 209-218.
15. X.S. Yang, Nature-Inspired Metaheuristic Algorithms, $2^{\text {nd }}$ ed. University of Cambridge, U.K.: Luniver Press, 2014, pp. 79-89.

16. S. Ding. Evolutionary artificial neural networks: A review, Journal of artificial intelligence review, vol. 39, no. 3, pp. 251-260, March 2013.

17. M.H. Hussain, I. Musirin, A.F. Abidin, and S.R.A. Rahim. Solving Directional Overcurrent Relay Coordination Problem using Artificial Bees Colony, World Academy of Science, Engineering and Technology, International Journal of Electrical, Electronic Science and Engineering, vol. 8, no. 5, pp. 705-710, May 2014.

18. I. Musirin and T.K.A. Rahman. Hybrid neural network topology (HNNT) for line outage contingency ranking, in National Power Engineering Conference, PECon, 2003, pp. 220-224.

19. D.N. Vishwakarma and Z. Moravej. ANN based directional overcurrent relay, in Proceedings of the IEEE Power Engineering Society Transmission and Distribution Conference, 2001, pp. 59-64.

20. T. Soares, F. Fernandes, H. Morais, P. Faria, and Z. Vale. ANN-Based LMP forecasting in a distribution network with large penetration of DG, in Proceedings of the IEEE Power Engineering Society Transmission and Distribution Conference, 2012, pp. 1-8.

21. S.S. Gururajapathy, H. Mokhlis, and H.A. Illias. Fault location and detection techniques in power distribution systems with distributed generation: A review, Renewable and Sustainable Energy Reviews, vol. 74, pp. 949-958, July 2017. 